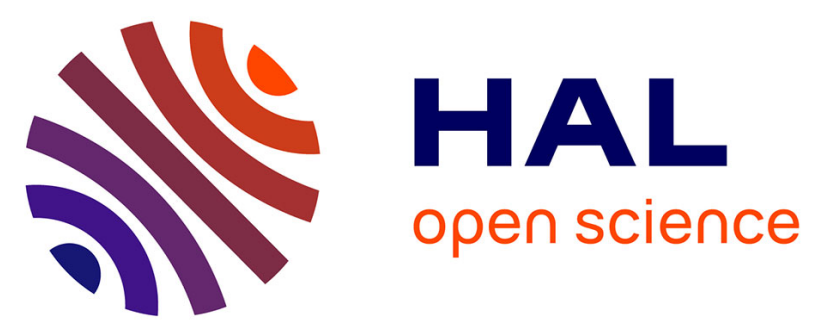

\title{
Tracking Charge Accumulation in a Functional Triazole-Linked Ruthenium-Rhenium Dyad Towards Photocatalytic Carbon Dioxide Reduction
}

Philipp Gotico, Thu-trang Tran, Aurelie Baron, Boris Vauzeilles, Christophe Lefumeux, Minh-huong Ha-thi, Thomas Pino, Zakaria Halime, Annamaria Quaranta, Winfried Leibl, et al.

\section{To cite this version:}

Philipp Gotico, Thu-trang Tran, Aurelie Baron, Boris Vauzeilles, Christophe Lefumeux, et al.. Tracking Charge Accumulation in a Functional Triazole-Linked Ruthenium-Rhenium Dyad Towards Photocatalytic Carbon Dioxide Reduction. ChemPhotoChem, In press, 10.1002/cptc.202100010 . hal03279658

\section{HAL Id: hal-03279658 \\ https://hal.science/hal-03279658}

Submitted on 6 Jul 2021

HAL is a multi-disciplinary open access archive for the deposit and dissemination of scientific research documents, whether they are published or not. The documents may come from teaching and research institutions in France or abroad, or from public or private research centers.
L'archive ouverte pluridisciplinaire HAL, est destinée au dépôt et à la diffusion de documents scientifiques de niveau recherche, publiés ou non, émanant des établissements d'enseignement et de recherche français ou étrangers, des laboratoires publics ou privés. 


\title{
Tracking Charge Accumulation in a Functional Triazole-Linked Ru-Re Dyad Towards Photocatalytic $\mathrm{CO}_{2}$ Reduction
}

\author{
Philipp Gotico, ${ }^{[a]}$ Thu-Trang Tran, ${ }^{[a]}$ Aurelie Baron, ${ }^{[b]}$ Boris Vauzeilles,${ }^{[b]}$ Christophe Lefumeux, ${ }^{[a]}$ Minh-
} Huong Ha-Thi, ${ }^{[a]}$ Thomas Pino, ${ }^{[a]}$ Zakaria Halime, ${ }^{[c]}$ Annamaria Quaranta,${ }^{[b]}$ Winfried Leibl, ${ }^{[b]}$ Ally

Aukauloo*[b]c]

[a] Dr. P. Gotico, Dr. T-T. Tran, C. Lefumeux, Dr. M-H. Ha-Thi, Dr. T. Pino

Université Paris Saclay, Institut des Sciences Moleculaire d'Orsay (ISMO)

91405 Orsay, France

[b] Dr. Z. Halime, Prof. A. Aukauloo

Université Paris Saclay, Institut de Chimie Moléculaire et des Matériaux d'Orsay (ICMMO)

91405 Orsay, France

[c] Dr. A. Baron, Dr. A. Quaranta, Dr. W. Leibl, Prof. A. Aukauloo

Université Paris Saclay, CEA, Institut de Biologie Intégrative de la Cellule (I2BC)

91191 Gif-sur-Yvette, France

Email: ally.aukauloo@universite-paris-saclay.fr

Supporting information for this article is given via a link at the end of the document.

\begin{abstract}
A novel triazole-linked ruthenium photosensitizer and rhenium catalyst dyad was synthesized and investigated for photoinduced charge accumulation using pump-pump-probe transient absorption spectroscopy. The triazole bridging ligand promoted weak electronic communication between the two units, resulting in an anodic shift of the reduction potentials of the Re moiety. Upon excitation, the first charge-separated state is formed at an apparent rate of $5.4 \times 10^{7} \mathrm{~s}^{-1}$, however a second excitation resulted in an efficient intramolecular reverse electron transfer preventing the twoelectron accumulation in the catalyst. Under continuous irradiation and use of sacrificial electron donors, photocatalytic $\mathrm{CO}_{2}$ reduction activities show good turnover numbers boosted by the effect of the sacrificial electron donor.
\end{abstract}

\section{Introduction}

Reduction of carbon dioxide $\left(\mathrm{CO}_{2}\right)$ into energy-rich compounds using solar light as an energy source provides a sustainable approach in solving the problem of global warming. Natural photosynthesis provides us with the scheme of how to use the abundant resources of water, $\mathrm{CO}_{2}$, and sunlight for the production of energy-rich carbohydrates. Mimicking this scheme usually involves synthesizing supramolecular assemblies that contain a photosensitizer (PS) able to harnesses solar energy, creating charge separated states, where the holes are used by oxidation catalysts to oxidize water to oxygen, and electrons are used by reduction catalysts to reduce $\mathrm{CO}_{2}$ into gaseous or liquid fuels.

One of the well-studied systems for photocatalytic $\mathrm{CO}_{2}$ reduction involves the rhenium carbonyl diimine complexes first reported by Lehn.$^{[1,2]}$ The great activity of the system stems from its robustness, efficiency, and the inherent selectivity of the doubly-reduced active form towards the $\mathrm{CO}_{2}$ substrate even in the presence of excess protons in the solution, favoring the production of $\mathrm{CO}$ from $\mathrm{CO}_{2}$ over the notoriously competing proton reduction to hydrogen gas. ${ }^{[3]}$ This complex is also considered as a "photo"-catalyst but requires a high-energy excitation in the ultraviolet region. As such, improvements on such systems include modification of the diimine and peripheral ligands to enhance catalysis and to shift the absorption properties into the visible range. ${ }^{[4-10]}$ Better performances were achieved by incorporating photosensitizers, with the archetypa ruthenium trisbipyridine $(\mathbf{R u})$, in supramolecular assemblies, to photo-activate the $R e$ catalyst in the visible spectral window as shown in Scheme 1. In this strategy, the choice of the linker/bridging ligand (L) is important as it plays important roles in conveying efficiently the electrons in an unidirectional fashion from the photosensitizer to the catalyst, and helping to maintain a spatial and temporal charge accumulation in the latter for the eventual use in the multi-electronic catalytic $\mathrm{CO}_{2}$ reduction.

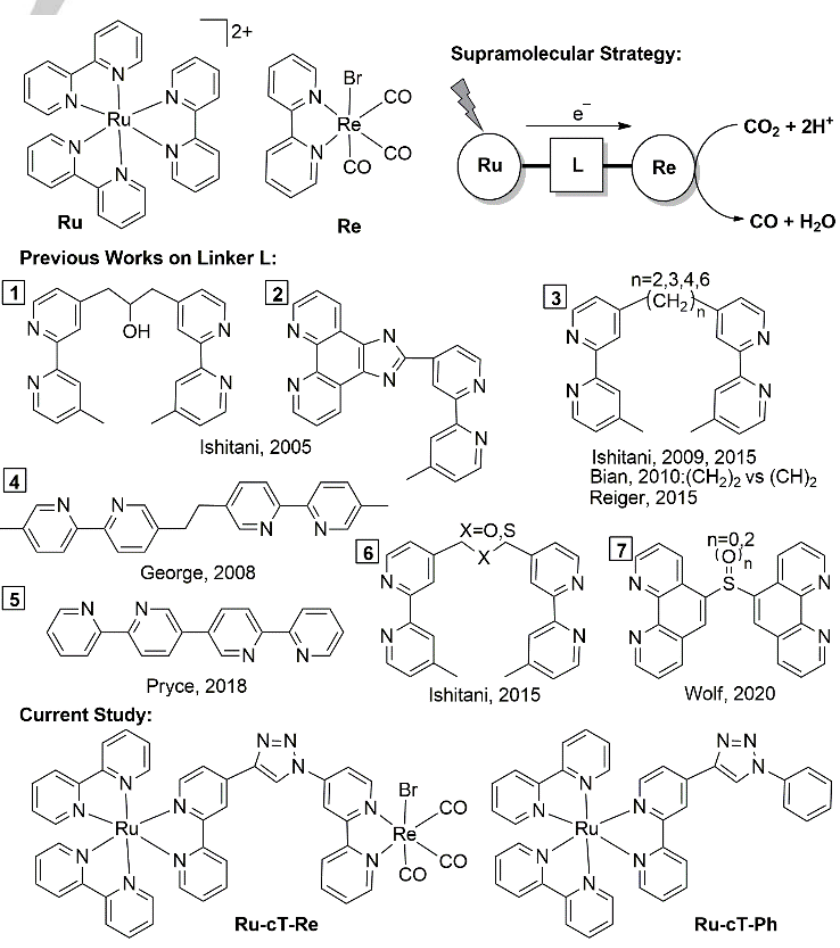


Scheme 1. Supramolecular strategy to link a Ruthenium photosensitizer and a Rhenium catalyst (top) using previously reported bridging ligand and the RuRe dyad system investigated in this study (bottom).

Supramolecular catalysts comprising such $\mathbf{R u}$ photosensitizer and $\mathbf{R e}$ catalyst have been extensively studied by the group of Ishitani. ${ }^{[11,12]}$ The highest photocatalytic turnover number $(\mathrm{TON}=3000$ ) was achieved for a dyad containing $\left[\mathrm{Ru}(\mathrm{dmb})_{3}\right]^{2+}$ and $\operatorname{Re}(\mathrm{dmb})(\mathrm{CO})_{2}\left(\mathrm{PPhF}_{3}\right)_{2}(\mathrm{dmb}=4,4$ '-dimethyl2,2'-bipyridine) linked through a saturated ethyl group (linker 3 with $n=2$ ), in dimethylformamide using 1,3-dimethyl-2-phenyl2,3-dihydro- $1 \mathrm{H}$ - benzo[d]imidazole $(\mathrm{BIH})$ as a sacrificial electron donor (SED) ${ }^{[13]}$ It has been suggested by the group of Bian that the introduction of a conjugated linker between the diimine moieties, such as $\mathrm{CH}_{2}=\mathrm{CH}_{2}$ in ligand 3 decreases the photocatalytic activity because bond conjugation lowers the $\pi^{*}$ orbital energy level of the Re catalyst unit which consequently decrease its reduction power. ${ }^{[14,15]}$ Similar results were obtained with the conjugated linker 2 regardless of the positioning of the $\mathrm{Ru}$ and $\mathrm{Re}$ moieties in either the phenanthroline or bipyridine groups, showing much inferior activities than their bimolecular counterparts. ${ }^{[16]}$ As such, weaker electronic communication, as observed in saturated alkyl chain bridges in $\mathbf{1}$ and $\mathbf{3}$, even though displaying almost isoenergetic thermodynamic drive for the first electron transfer, were the mostly recommended and used bridge in designing supramolecular assemblies. ${ }^{[13,17-24]}$ Ishitani and colleagues have investigated the intramolecular electron transfer in these systems, using time-resolved infrared absorption measurements in the presence of irreversible electron donors, and showed a very rapid electron transfer $\left(>2 \times 10^{7} \mathrm{~s}^{-1}\right)$, confirming that such saturated linkers adequately transfer photo-produced electrons to the catalyst unit. ${ }^{[25]}$

Elaborating further on bridging ligand design, it was found that increasing the alkyl chain length from two carbon atoms to four or six, lowered the photocatalytic activity. ${ }^{[2]}$ On the other hand, positioning the linker in the meta positions of the bipyridine ring and removing the alkyl chain bridge as in linker 5 induces a weak electronic communication between the metal centers and showed lower photocatalytic activity than their bimolecular counterpart. ${ }^{[26]}$ Decorating the alkyl linker with an electronegative oxygen atom as in $\mathbf{6}$ increased the thermodynamic drive for the first electron transfer from $\mathrm{Ru}$ to $\mathrm{Re}$ compared to its carbon analogue, and consequently gave better photocatalytic activities. ${ }^{[27]}$ Replacing the oxygen with a sulfur atom in linker 6 , however, resulted to a less stable system as the dyad splits into its mononuclear forms during photo-irradiation. Recently, the group of Wolf reported an enhanced photocatalytic activity when using an oxidized sulfone group $\left(\mathrm{SO}_{2}\right)$ in linker 7 compared to its sulfide analogue and attributed enhancement to better electronic communication between the metal centers, resulting in positive shifts of the reduction potentials. ${ }^{[28]}$ However the system faced similar photo-degradation concerns indicating the vulnerability of the C-S bond.

From these investigations on different bridging ligands, there appears to be an unexpected contradiction to the rationale of a supramolecular design in creating an efficient flow of electron from the photosensitizer unit to the catalyst. On one hand, the use of linkers promoting strong electronic communication accelerates electron transfer from the photosensitizer to the catalyst but results in lowered photocatalytic activities, while on the other hand, saturated alkyl linkers provide better photocatalytic activities even with low thermodynamic drive for the first photo-induced electron transfer. This counter-intuitive results possibly suggests that the ratelimiting step in the photocatalytic $\mathrm{CO}_{2}$ reduction in these systems is not the first electron transfer but the subsequent steps (catalyst-centered processes such as halide loss, two-electron accumulation forming the doubly-reduced active form, interaction of the active form with the substrate, and succeeding protonation and electron transfer steps). ${ }^{[29-31]}$ As the previous systems mostly focused on the effect of the bridging ligand on the formation of the one-electron reduced species (OERS) of the $\mathrm{Re}$ catalyst, the thermodynamics and kinetics of the photoinduced formation of the catalytically active doubly-reduced form of the catalyst is seldom reported. To address this point, in this study we synthesized a new $\mathrm{Ru}-\mathrm{Re}$ dyad linked by a triazole moiety (Ru-cT-Re) and investigated its photophysical and photocatalytic properties. The triazole linker is a common bridge for supramolecular systems readily prepared by "click" chemistry, a simple and efficient covalent ligation methodology. ${ }^{[32]}$ Moreover, it has been reported to promote good electron transfer in supramolecular dyads and the rigidity of such bridge prevents any unwanted charge transfer. ${ }^{[33-35]}$ We investigated the first photo-induced electron transfer from the $\mathrm{Ru}$ photosensitizer to the Re catalyst using nanosecond laser flash photolysis and for the first time attempted to track the photoinduced two-electron accumulation in the Re moiety. Together with photocatalytic optimizations, our results provide critical implications of supramolecular design, especially if such strategies will be employed in hybrid interfaces of photo-electrochemical cells.

\section{Results and Discussion}

\section{Synthesis}

The Ru-cT-Re dyad was synthesized using the coppercatalyzed azide-alkyne cycloaddition (popularly known as 'click' chemistry) starting from the versatile $\mathrm{Ru}-\mathrm{C} \equiv \mathrm{CH}$ synthon (compound A, Scheme 2) ${ }^{[35]}$ and an azide-substituted bipyridine ligand used in the next step to introduce the Re triscarbonyl catalyst (Scheme 2). Similar strategy has been utilized for the facile incorporation of various catalytic and donor/acceptor units to a photosensitizer, ${ }^{[3,33-36]}$ with the Ru-Ni cyclam dyad been the most relevant for photocatalytic $\mathrm{CO}_{2}$ reduction. ${ }^{[37]}$

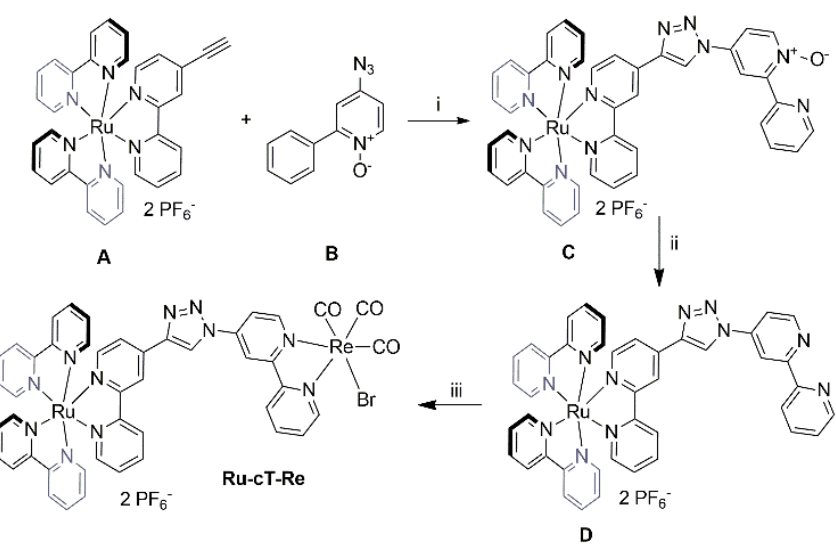


Scheme 2. Synthetic route for the preparation of the $\mathbf{R u - c T - R e ~ d y a d . ~}$ Reagents and conditions: (i) $\mathrm{CuSO}_{4} .5 \mathrm{H}_{2} \mathrm{O}$, sodium ascorbate, $\mathrm{CH}_{2} \mathrm{Cl}_{2} / \mathrm{H}_{2} \mathrm{O}$ (77\%); (ii) $\mathrm{PCl}_{3}, \mathrm{CH}_{2} \mathrm{Cl}_{2}(79 \%)$; (iii) [Re(CO) $\left.)_{5} \mathrm{Br}\right], \mathrm{THF} / \mathrm{CH}_{3} \mathrm{CN}(86 \%)$.

\section{Absorption and Emission Properties}

The absorption spectrum of the Ru-cT-Re dyad displays absorption features characteristic of both mononuclear complexes Ru-cT-Ph and Re (Figure 1a). The strong ${ }^{1}$ MLCT absorptions between 400 and $500 \mathrm{~nm}$ (peak at $464 \mathrm{~nm}$ ), characteristic of the $\mathrm{Ru}(\mathrm{II})$ unit, is clearly visible in the spectrum whereas the weaker higher energy ${ }^{1} \mathrm{MLCT}$ absorption characteristic of the $\operatorname{Re}(\mathrm{I})$ terminus is apparent as an increased absorbance in the $350-400 \mathrm{~nm}$ region. Compared to the $\mathbf{R e}$ catalyst alone, the extended absorption of the Ru-cT-Re dyad in the visible range is beneficial for photocatalytic applications as the strong absorption at $400-500 \mathrm{~nm}$ coincides with the intense irradiance from the solar spectrum. The triazole linker between the photosensitizer and the catalyst resulted in (i) a slight redshift in the absorption spectra, and (ii) increased absorption in the dyad as compared to the spectral summation of the Ru-cT$\mathbf{P h}$ and $\mathbf{R e}$ reference complexes. These spectral changes are characteristic of a weak electronic communication between the two metals in the system. ${ }^{[14,16]}$ The emission spectrum of the RucT-Re shows an absorption maximum at $633 \mathrm{~nm}$ corresponding to the triplet metal-to-ligand charge transfer $\left({ }^{3} \mathrm{MLCT}\right)$ excited state of the Ru moiety exhibiting a long-lived lifetime of $1085 \mathrm{~ns}$ (Table 1). This Ru-cT-Re emission is $5 \mathrm{~nm}$ red-shifted compared to the Ru-cT-Ph reference but $20 \mathrm{~nm}$ red-shifted compared to the $\mathbf{R u}$ reference. Both the triazole-linked Ru-cT-Re dyad and Ru-cT-Ph reference have longer-lived emission lifetimes and higher emission quantum yields compared to the Ru reference, and we have previously ascribed this to the partial delocalization of the LUMO on the triazole-linked bipyridine. ${ }^{[35]}$ The similarity of the excited state lifetimes of Ru-cT-Re and Ru-cT-Ph indicates that no energy or electron transfer occurred from the excited state of Ru moiety to the Re moiety.
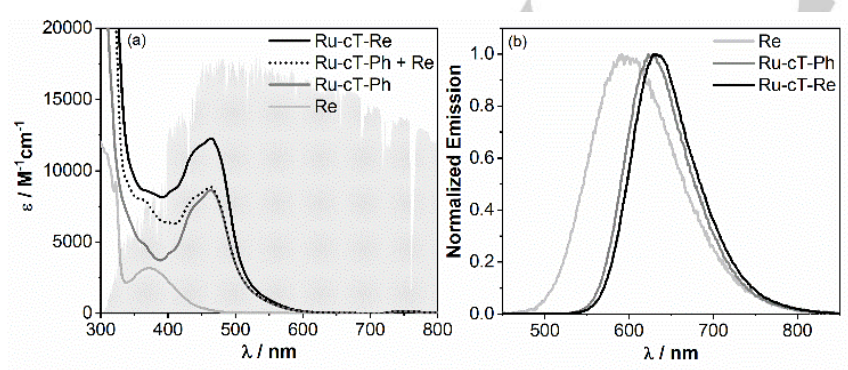

Figure 1. Absorption spectra of Ru-cT-Re in comparison with mononuclear references $\mathbf{R u - c T - P h}$ and $\mathbf{R e}$. Dotted lines show spectral summation of the reference complexes. Shaded area represents solar irradiation spectrum. (b) Normalized emission spectra of the complexes in Ar-degassed ACN/ $\mathrm{H}_{2} \mathrm{O}$.

Table 1. Emission data of the complexes studies in Ar-degassed $A C N / \mathrm{H}_{2} \mathrm{O}$.

\begin{tabular}{lcccc}
\hline Complex & $\lambda_{\mathrm{abs}} / \mathrm{nm}$ & $\boldsymbol{\lambda}_{\mathrm{em}} / \mathbf{n m}$ & $\boldsymbol{T} / \mathbf{n s}$ & $\boldsymbol{\Phi}_{\mathrm{em}}$ \\
\hline Ru-cT-Re & 464 & 633 & 1085 & 0.113
\end{tabular}

\begin{tabular}{lcccc} 
Ru-cT-Ph & 464 & 628 & 1081 & $0.097^{[35]}$ \\
$\mathbf{R u}$ & 454 & 612 & 900 & $0.059^{[38]}$ \\
$\mathbf{R e}$ & 372 & 599 & 25 & $0.005^{[39]}$ \\
\hline
\end{tabular}

Table 2. Redox potentials $\left(E_{1 / 2}\right)$ of the complexes in Ar-saturated acetonitrile with $100 \mathrm{mM}$ TBAP measured in $\mathrm{V} v s \mathrm{Fc}^{0 /+}$.

\begin{tabular}{|c|c|c|c|c|c|c|c|}
\hline Complex & $\mathbf{R e}^{1 / 1 / 1}$ & $R u^{\prime \prime \prime \prime I I ~}$ & $\operatorname{ReL}^{0 /-}$ & $\operatorname{Re}^{1 / 0} \mathbf{L}^{0 /-}$ & RuL $^{0 /-}$ & $\mathrm{RuL}^{-/ 2-}$ & $\mathrm{RuL}^{2-/ 3-}$ \\
\hline Ru-cT-Re & $1.01^{[\mathrm{a}]}$ & 0.87 & $-1.56^{[a]}$ & $-1.98^{[b]}$ & -1.76 & $-1.98^{[\mathrm{b}]}$ & -2.24 \\
\hline Ru-cT-Ph & - & & - & & -1.75 & -1.96 & -2.20 \\
\hline Ru & - & 0.85 & - & - & -1.77 & -1.97 & -2.20 \\
\hline $\mathrm{Re}$ & $0.92^{[a]}$ & & -1.78 & -2.10 & - & - & - \\
\hline
\end{tabular}

[a] Peak potential of irreversible peak. [b] Two-electron peak
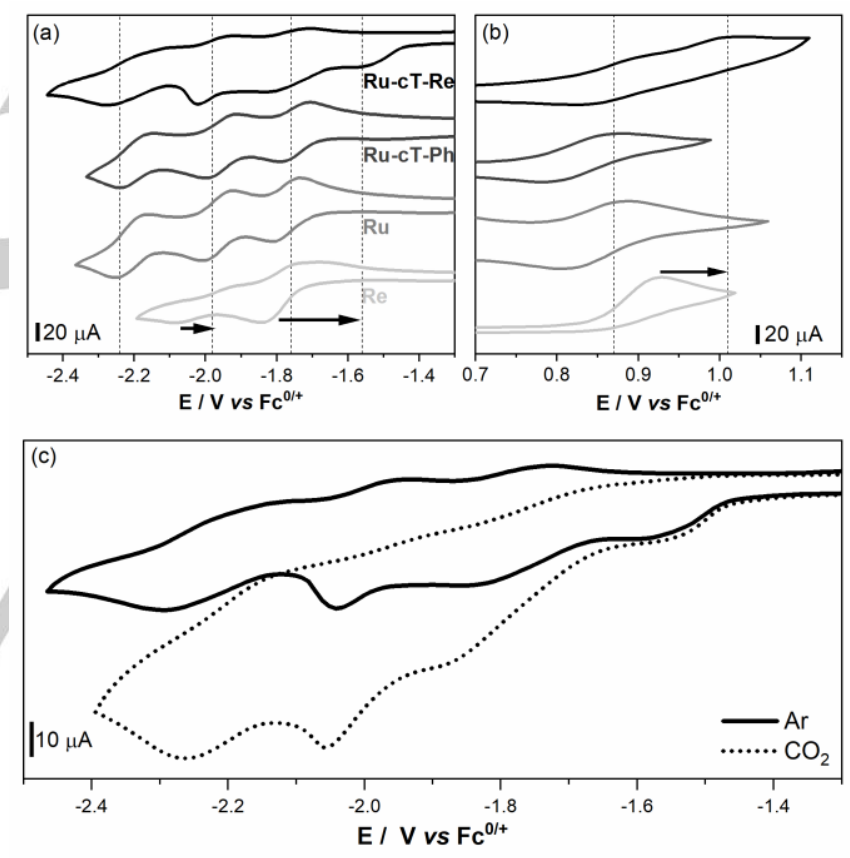

Figure 2. CVs showing (a) reduction and (b) oxidation potentials of Ru-cT-Re dyad (black) in comparison with Ru-cT-Ph, $\mathbf{R u}$, and $\mathbf{R e}$ in $\mathrm{Ar}$ and (c) in $\mathrm{CO}_{2}$ saturated ACN solution containing 100 mM TBAP. Dashed lines in (a) and (b) correspond to potentials of Ru-cT-Re reported in Table 2. Arrows indicate the shift of the Re-related redox peaks in Ru-cT-Re.

\section{Electrochemical Characterization}

The cyclic voltammograms (CV) in Figure 2 show characteristic oxidation and reduction waves of the $\mathbf{R u - c T - R e}$ dyad and of the mononuclear reference complexes $\mathbf{R u - c T - P h , ~ R u}$, and $\mathbf{R e}$. Two oxidation waves were observed for the heterometallic complex Ru-cT-Re: (i) a first reversible oxidation wave at $0.87 \mathrm{~V}$ attributed to $\mathrm{Ru}^{\mathrm{III/I}}$ and (ii) a second $\mathrm{Re} \mathrm{e}^{\mathrm{II/I}}$ irreversible peak at $1.01 \mathrm{~V}$ due to the rapid bromine loss (Figure 2b, Table 2). Both peaks were shifted anodically in the dyad compared to the 
mononuclear complexes possibly due to the presence of another metal asserting an electron withdrawing effect. It is observed however, that the Ru moiety is not significantly shifted compared to the $90 \mathrm{mV}$ shift displayed for the Re moiety.

The three reduction waves of the Ru-cT-Ph at $-1.75 \mathrm{~V}$, $1.96 \mathrm{~V}$, and $-2.20 \mathrm{~V}$ are attributed to the reduction of the three bipyridyl ligands, similar to the three reduction potentials of $\mathbf{R u}$, (Figure 2a, Table 2). The presence of the triazole linker in $\mathbf{R u}-$ cT-Ph did not significantly shift the reduction potentials of $\mathbf{R u}$. Similarly, the reduction potentials at $-1.76 \mathrm{~V},-1.98 \mathrm{~V}$, and -2.24 $\mathrm{V}$ of the Ru-cT-Re dyad complex are attributed to the bipyridyl reductions of the $R u$ moiety. The small shifts in the reduction potential of the Ru moiety are consistent with the shifts observed in oxidation. These results indicate that the triazole bridging with the $\mathrm{Re}$ catalyst did not significantly affect the redox properties of Ru photosensitizer.

The first reduction potential of Ru-cT-Re observed at -1.56 $\mathrm{V}$ is attributed to the reduction of the bipyridyl ligand of rhenium moiety. This is confirmed by the following comparisons: (i) the wave is irreversible possibly due to ligand loss $\left(\mathrm{Br}^{-}\right)$in the rhenium which is similarly observed for the mononuclear $\mathbf{R e}$ complex, (ii) a catalytic wave is observed just after this wave when the solution is saturated with $\mathrm{CO}_{2}$ (Figure 2c) indicating the electrocatalytic activity of the $\mathrm{Re}$ moiety towards $\mathrm{CO}_{2}$ reduction, and (iii) the wave is observed neither for Ru-cT-Ph nor for Ru reference complexes and therefore can only come from the Re moiety. The large anodic shift $(220 \mathrm{mV})$ of the reduction potential of the $\mathrm{Re}$ moiety in the $\mathbf{R u - c T - R e}$ dyad complex is consistent with the observed anodic shift of the $R e$ oxidation potential but the effect is stronger for the reduction potential because it is a bipyridyl-centered reduction. Since the first reduction potential of the Re moiety is less negative than that of the Ru moiety, intramolecular electron transfer from the reduced Ru moiety to the Re moiety in the ground state should proceed smoothly $(\Delta G=-220 \mathrm{meV})$. The second reduction of the Re moiety, reported to be a metal-centered reduction, is expected to occur at $-1.98 \mathrm{~V}$ in the dyad due to the 2-electron nature of the reduction wave. As such, it can be expected that there will be an uphill thermodynamic drive $(\Delta G=+220 \mathrm{meV})$ for the second electron accumulation in the Re moiety from the reduced $\mathrm{Ru}$.

\section{Tracking the First Charge Separated State $\left(1^{\text {st }} \mathrm{CSS}\right)$}

The activation of the $\mathbf{R e}$ catalyst by the $\mathbf{R} \mathbf{u}$ photosensitizer was previously investigated by our group in a bimolecular system with sodium ascorbate (Asc) as a reversible electron donor in Ar-saturated $\mathrm{ACN} / \mathrm{H}_{2} \mathrm{O}$ solution. ${ }^{[40]}$ We have utilized nanosecond transient absorption spectroscopy and upon detailed spectroscopic and kinetic analyses, we were able to distinguish the bipyridyl-based reductions between $\mathbf{R u}$ and $\mathbf{R e}$. The oneelectron reduced species (OER) of $\mathbf{R u}$ has a characteristic transient absorption at $510 \mathrm{~nm}$, and although the OER of Re has similar transient absorption in this same region, it also possesses an additional absorption at $450 \mathrm{~nm}$ where the OER of $\mathbf{R u}$ would otherwise have a bleaching. Therefore, following the absorption changes at these wavelengths, we were able to estimate a diffusion-limited electron transfer rate of $4.8 \times 10^{9} \mathrm{M}^{-}$ ${ }^{1} \mathrm{~s}^{-1}$ from the OER of $\mathbf{R u}$ to $\mathbf{R e}$, even though there is almost an isoenergetic thermodynamic drive for this process $(\Delta G \sim+10$ $\mathrm{meV})$.
The Ru-cT-Re dyad was similarly investigated here and the transient absorption spectra at various delay times are shown in Figure 3. At these short time scale $(0-100 \mathrm{~ns})$, the transient spectra are characterized by an initial depletion of the Ru ground-state MLCT band at $450 \mathrm{~nm}$, followed by an intense absorption growth at $400-600 \mathrm{~nm}$ region. In comparison with the transient absorption spectra of Ru-cT-Ph (Figure S1), one

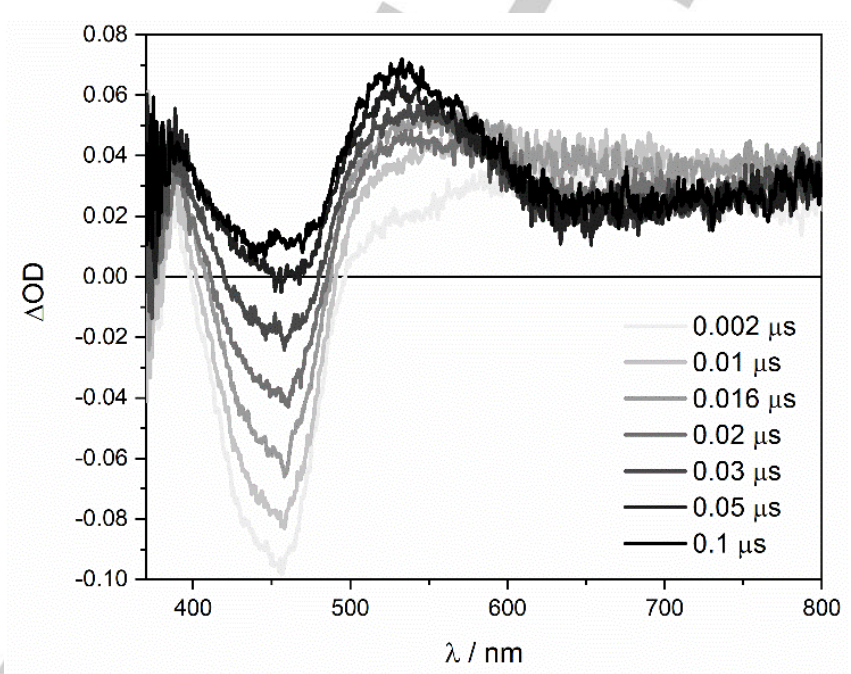

distinct observation is the formation of positive absorption at 450 $\mathrm{nm}$, which is consistent with the OER of Re, formed upon fast intramolecular electron transfer.

Figure 3. Transient absorption spectra of Ru-cT-Re $(57 \mu \mathrm{M})$ and Asc (100 $\mathrm{mM}$ ) in Ar-saturated $\mathrm{ACN} / \mathrm{H}_{2} \mathrm{O}$ in various delay times after single-pulse excitation at $460 \mathrm{~nm}$ (6.5 mJ per pulse).

Figure 4. Transient absorption decays at selected wavelengths of Ru-cT-Re $(57 \mu \mathrm{M})$ and Asc $(100 \mathrm{mM})$ in Ar-saturated $\mathrm{ACN} / \mathrm{H}_{2} \mathrm{O}$ after single-pulse excitation at $460 \mathrm{~nm}$ (6.5 mJ per pulse). Inset: decay-associated difference spectra: 19 ns attributed to decay of $\mathrm{Ru}^{\mathrm{II}_{*}}-\mathrm{cT}-\mathrm{Re}^{\mathrm{l}}$ and $c$ attributed to transient spectra of $1^{\text {st }}$ CSS

The kinetic traces at representative wavelengths are shown in Figure 4, and provide a clear picture of the mechanism of the first photo-induced charge-separation process. Upon laser excitation and formation of the excited state $R u^{11 *}-\mathrm{cT}-\mathrm{Re}$ (bleaching at $450 \mathrm{~nm}$ ), the species relaxes to concomitantly give oxidized $\mathrm{Asc}^{+}$at $390 \mathrm{~nm}$ and the OER of Re (formal $\mathrm{Re}^{0}$ species) with characteristic absorption at $450 \mathrm{~nm}$ and $500 \mathrm{~nm}$. This is indicative of a first electron transfer between Asc and

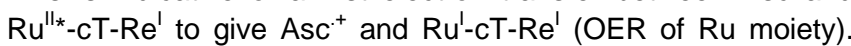
The latter then undergoes a very fast intramolecular electron transfer to form $\mathrm{Ru} u^{\prime \prime}-\mathrm{cT}-\mathrm{Re}^{0}$. The kinetic traces are globally fitted

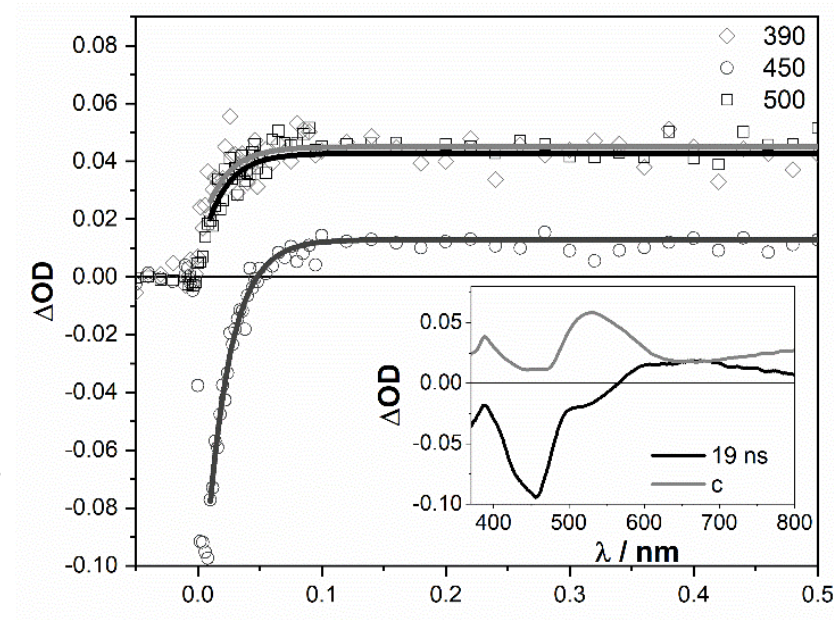




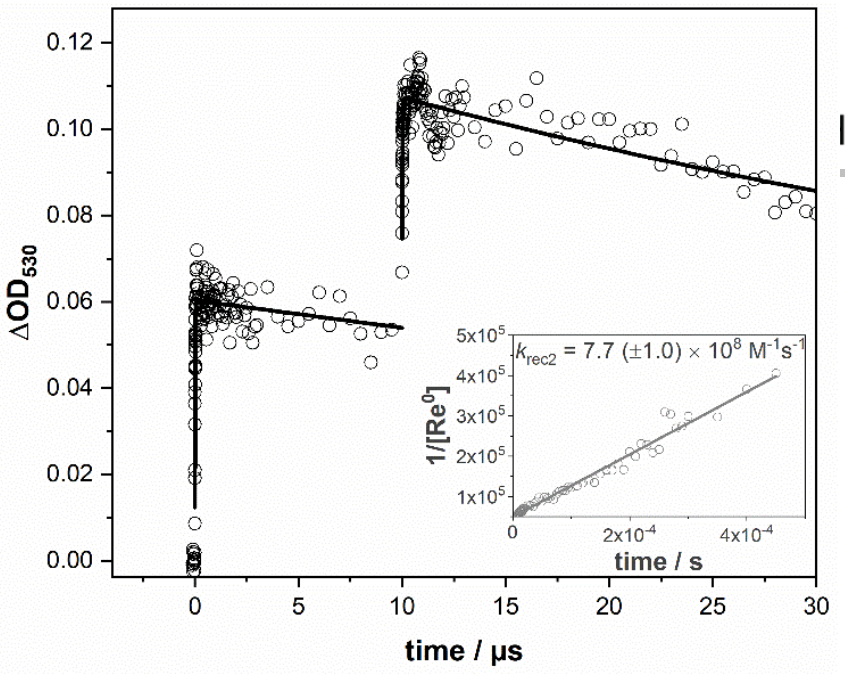

using a monoexponential function $\left[a_{1} \exp (-t / T)+\mathrm{c}\right]$ and satisfactory fits gave a time constant of $T=19( \pm 3) \mathrm{ns}$ corresponding to an apparent rate constant $k_{a p p 1}=5.3( \pm 0.3) \times$ $10^{7} \mathrm{~s}^{-1}$. The decay-associated difference spectrum (DADS) with time constant $19 \mathrm{~ns}$ is attributed to the decay of $\mathrm{Ru}^{1 /{ }^{*}}$-cT-Re together with the rise of $\mathrm{Ru}^{\mathrm{II}}-\mathrm{cT}-\mathrm{Re}^{0}$ (shoulder at $520 \mathrm{~nm}$ ) while the non-decaying component $c$ is attributed to the spectrum of the $1^{\text {st }}$ charge-separated state: Asc $^{+}$and $R u^{\prime \prime}-c T-R e^{0}$. These species then undergo charge recombination at longer time scale occurring with a second order kinetic rate constant $k_{\text {rec2 } 2}=9.6$ $( \pm 1.0) \times 10^{8} \mathrm{M}^{-1} \mathrm{~s}^{-1}$ (Figure S2). The final $\Delta A_{509}=0.07$ corresponds to the formation of $\sim 12.3( \pm 0.9) \mu \mathrm{M}$ of $\mathrm{Ru}^{\mathrm{II}}-\mathrm{cT}-\mathrm{Re}^{0}$ (using $\left.\Delta \varepsilon=5700 \mathrm{~m}^{-1} \mathrm{~cm}^{-1}\right),{ }^{[41]}$ that is $21 \%$ of the ground state population.

\section{Tracking the Second Charge Separated State $\left(2^{\text {nd }}\right.$ CSS)}

To investigate the second-electron accumulation in the $R e$ moiety of the Ru-cT-Re dyad, a second nanosecond laser excitation was applied at $460 \mathrm{~nm}$ separated from the first excitation by $10 \mu \mathrm{s}$, a delay where the $1^{\text {st }} \mathrm{CSS}$ is optimal and the $\mathrm{Ru}$ photosensitizer is regenerated. The transient absorption spectra after the second laser excitation (Figure 5) did not show any new spectral changes compared to the changes after the first flash excitation (Figure 3). The transient absorption kinetics at short (Figure S3) and long time scale (Figure 6) show no significant differences compared to the first excitation indicating that a very similar charge transfer mechanism occurs upon second excitation. Of note, the doubly-reduced form of Re is expected to absorb at $570 \mathrm{~nm}$ with $\varepsilon=12100 \mathrm{M}^{-1} \mathrm{~cm}^{-1}{ }^{[41]}$ From the maximum $\Delta A_{509}=0.06$ after second excitation (Figure 5), the concentration of $R u^{\prime \prime}-c T-R e^{0}$ created by the second pump is estimated to be $10.5( \pm 0.9) \mu \mathrm{M}$, corresponding to $24 \%$ of the remaining ground state population, a very similar efficiency for the $1^{\text {st }}$ CSS. In addition, the second order recombination rate is calculated to be $k_{\text {rec2 }}=7.7( \pm 1.0) \times 10^{8} \mathrm{M}^{-1} \mathrm{~s}^{-1}$ (Figure 6 inset), closely similar to the one calculated for the first excitation.

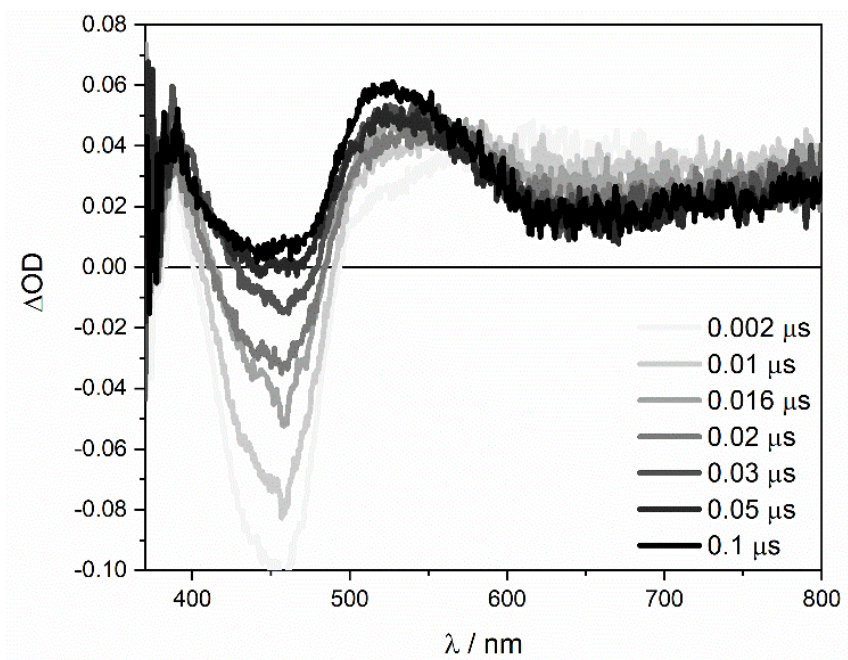

Figure 5. Transient absorption spectra of Ru-cT-Re $(57 \mu \mathrm{M})$ and Asc $(100$ $\mathrm{mM}$ ) in Ar-saturated $\mathrm{ACN} / \mathrm{H}_{2} \mathrm{O}$ in various delay times after double-pulse excitation at $460 \mathrm{~nm}$ delayed by $10 \mu \mathrm{s}$ : first pump at $20 \mathrm{~Hz}$, second pump at 10 $\mathrm{Hz}$. Asc $(100 \mathrm{mM})$ in Ar-saturated $\mathrm{ACN} / \mathrm{H}_{2} \mathrm{O}$ after first and second laser excitation at $460 \mathrm{~nm}$. The effect of the first pump from $10 \mu \mathrm{s}$ was added to the double pulse measurement to get the total quantity of the charge-separated state after the second pump. Inset: kinetic trace plotted as $1 /\left[\mathrm{Re}^{0}\right]$ vs time after double flash excitation.

Figure 7. Energy level diagram showing rate constants for the sequential charge accumulation in Ru-cT-Re dyad. Orange arrows: excitation; blue arrows: deactivation pathways; dashed arrows: recombination reaction; red arrows: unproductive competitive reactions; dotted level: expected states for $2^{\text {nd }}$ CSS. The scheme is simplified for clarity: (i) changes in formal oxidation states are shown, (ii) involvement of Asc in $(1,4)$ and oxidized $\mathrm{Asc}^{+}$in $(6,7$ $\left.k_{\text {rec1 }}, k_{\text {rec2 }}\right)$ are not explicitly shown. Rate constants: $k_{\text {app } 1} \sim 5.4( \pm 0.3) \times 10^{7} \mathrm{~s}^{-1}$ for steps (1) and (2) and $k_{\mathrm{rec} 2}=7.7( \pm 1.0) \times 10^{8} \mathrm{M}^{-1} \mathrm{~s}^{-1}$.

These results indicate that excitation of the $1^{\text {st }}$ CSS did not allow the formation of the accumulative charge transfer state under our conditions. This could be explained by a rapid quenching of $\mathrm{Ru}^{\mathrm{ll} *}-\mathrm{cT}-\mathrm{Re}^{0}$ by reverse electron transfer to form $\mathrm{Ru}^{\prime}-\mathrm{cT}$-Re' (process 3 in Figure 7) followed by an intramolecular regeneration of the $\mathrm{Ru}^{\mathrm{II}}-\mathrm{cT}-\mathrm{Re}^{0}$ state (process 2 ). All these intramolecular reactions are expected to be faster than the intermolecular quenching of $\mathrm{Ru} \mathrm{u}^{11 *}-\mathrm{cT}-\mathrm{Re}^{0}$ by Asc to ideally create the two-electron accumulated form $\mathrm{Ru}^{\prime \prime}-\mathrm{cT}-\mathrm{Re}^{-1}\left(k_{3}>k_{e t 2}\right)$. This

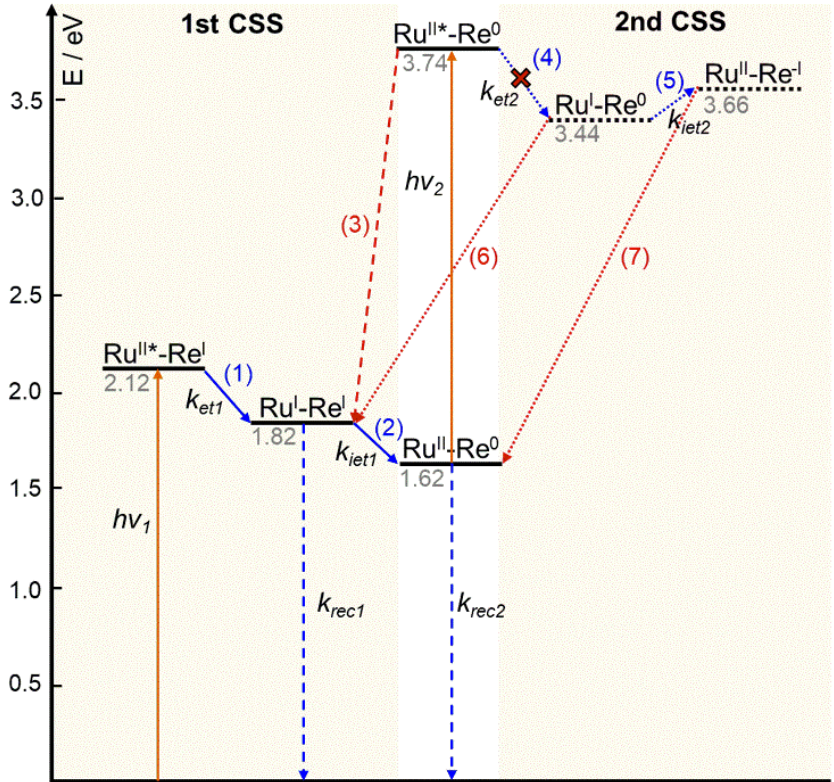

efficient reverse electron transfer have been similarly observed for other supramolecular systems in literature preventing the productive charge accumulation in catalytic/acceptor units. ${ }^{[42-47]}$ 
To avoid such intramolecular competitive unproductive pathway, a bimolecular system was also investigated and similar lack of charge accumulation on the $\mathbf{R e}$ catalyst was observed (Figure S4). This could come from the uphill thermodynamic drive $(\Delta G \sim+330 \mathrm{meV})$ for the electron transfer between $\mathrm{Ru}^{\prime}$ and $\mathrm{Re}^{0}$ to form $\mathrm{Ru}^{\prime \prime}$ and $\mathrm{Re}^{-1}$. A similar uphill thermodynamic drive $(\Delta G \sim+200 \mathrm{meV})$ is expected in the dyad to form $R u^{\prime \prime}-\mathrm{cT}-\mathrm{Re}^{-1}$ (process 5 ) hinting to the eventual difficulty of photo-induced charge accumulation in the supramolecular system. Similar constraint can be expected for the other Ru-Re systems listed in Scheme 1 especially those that do not establish good electronic communication, as the relevant redox potentials would not be far from the bimolecular systems where the second electron accumulation in the $\mathrm{Re}$ from the $\mathrm{Ru}$ ' photo-reductant is highly endergonic.

\section{Photocatalytic Activities}

Even though photophysical investigation of the photo-induced processes in the Ru-cT-Re dyad subtly suggests the difficulty of two-electron accumulation in the Re moiety, under continuous illumination and use of sacrificial electron donors the system still shows the possibility of photocatalytic $\mathrm{CO}_{2}$ reduction. The optimization of the photocatalytic conditions are presented in Table 3. From these optimizations, the following can be deduced: (i) the use of 1,3-dimethyl-2-phenylbenzimidazoline (BIH) as SED compared to 1-benzyl-1,4-dihydronicotinamide (BNAH) gave better photocatalytic activities mainly attributed to the high quenching efficiency of BIH $\left(k_{\mathrm{q}}=3 \times 10^{9} \mathrm{M}^{-1} \mathrm{~s}^{-1}\right)$ than BNAH $\left(k_{\mathrm{q}}=3 \times 10^{8} \mathrm{M}^{-1} \mathrm{~s}^{-1}\right)^{[40]}$ and the participation of the highly reducing deprotonated oxidized radical $\left[E\left(B I^{*}\right)=-2.02 \vee v s\right.$ $E\left(\mathrm{BNA}^{\circ}\right)=-1.42 \mathrm{~V}$ vs Fc] ${ }^{[11,13,48,49]}$; (ii) the TONs of the Ru-cT-Re dyad is inferior to its bimolecular counterpart, as similarly observed for other Ru-Re dyads allowing weak electronic communication $^{[14,16]}$; and (iii) the introduction of the $R u$ photosensitizer, whether in bimolecular or supramolecular fashion, is always beneficial compared to using the Re catalyst alone as it provides sensitization in the visible region and the needed spatial and temporal separation of roles between photon capture, charge accumulation and catalysis.

The disparity between the investigation of the fast photoinduced processes and the photocatalytic performances of the Ru-cT-Re dyad and its bimolecular counterpart, highly suggests that despite efforts in establishing good thermodynamic photoinduced electron transfer from the photosensitizer to the catalyst for eventual charge accumulation and catalysis, the noninnocent role of the sacrificial electron donor plays critical role in determining the photocatalytic activities. We propose that for the Ru-cT-Re dyad and similar systems, the supramolecular assembly is beneficial in promoting a fast first photo-induced intramolecular electron transfer to accumulate the one-electron reduced species of the catalyst, but the eventual charge accumulation to form the more active doubly-reduced form of the catalyst is provided by a dark reaction from the radical byproduct of the SED (Figure 8). The investigation is still open as to how supramolecular assemblies or sacrificial electron sources play further roles in the catalysis and how degradation mechanism alters photocatalytic performances. However, with the perspective that these supramolecular systems would be incorporated in a complete photo-electro-chemical cell with a

thermodynamically favorable conveyance of electrons from the oxidation of water (void of any non-innocent highly reducing radicals), the design and thermodynamic requirements should be reconsidered to access the more catalytically active forms of the catalyst.

Table 3. Optimization of the reaction conditions for the photocatalytic $\mathrm{CO}_{2}$ to CO reduction.

\begin{tabular}{|c|c|c|c|c|c|}
\hline Entry & System ${ }^{[a]}$ & SED ${ }^{[b]}$ & Solvent $^{[\mathrm{cl}}$ & $\mu \mathrm{mol} \mathrm{CO}$ & $\operatorname{TON}^{[d]}$ \\
\hline 1 & Ru-cT-Re & Asc & $\mathrm{DMF}+10 \% \mathrm{H}_{2} \mathrm{O}$ & - & - \\
\hline 2 & Ru-cT-Re & BNAH & DMF & - & - \\
\hline 3 & Ru-cT-Re & BNAH & DMF + TEOA & - & - \\
\hline 4 & Ru-cT-Re & $\mathrm{BNAH}$ & $\mathrm{DMF}+10 \% \mathrm{H}_{2} \mathrm{O}$ & 0.6 & 5 \\
\hline 5 & $\mathbf{R u}+\mathbf{R e}$ & BNAH & $\mathrm{DMF}+10 \% \mathrm{H}_{2} \mathrm{O}$ & 1.2 & 8 \\
\hline 6 & $\mathbf{R e}$ & BNAH & $\mathrm{DMF}+10 \% \mathrm{H}_{2} \mathrm{O}$ & 0.3 & 3 \\
\hline 7 & Ru-cT-Re & $\mathrm{BIH}$ & $\mathrm{DMF}+10 \% \mathrm{H}_{2} \mathrm{O}$ & 38 & 257 \\
\hline 8 & $\mathbf{R u}+\mathbf{R e}$ & $\mathrm{BIH}$ & $\mathrm{DMF}+10 \% \mathrm{H}_{2} \mathrm{O}$ & 78 & 520 \\
\hline 9 & Ru & $\mathrm{BIH}$ & $\mathrm{DMF}+10 \% \mathrm{H}_{2} \mathrm{O}$ & 0.5 & 3 \\
\hline 10 & $\mathbf{R e}$ & $\mathrm{BIH}$ & $\mathrm{DMF}+10 \% \mathrm{H}_{2} \mathrm{O}$ & 5.6 & 37 \\
\hline 11 & - & $\mathrm{BIH}$ & $\mathrm{DMF}+10 \% \mathrm{H}_{2} \mathrm{O}$ & - & - \\
\hline
\end{tabular}

[a] $50 \mu \mathrm{M}$ concentration (equimolar when using bimolecular mixture), light source: LED lamp with $\lambda_{\mathrm{em}}=463 \mathrm{~nm}\left(\mathrm{FWHM} 50 \mathrm{~nm}, 180 \mathrm{~W} / \mathrm{m}^{2}\right), 2 \mathrm{~h}$ irradiation. [b] SED = sacrificial electron donor, Asc $=$ sodium ascorbate, $\mathrm{BNAH}=1$-benzyl-1,4-dihydronicotinamide, $\quad \mathrm{BIH}=1,3$-dimethyl-2 phenylbenzimidazoline. [c] DMF=dimethylformamide, TEOA = triethanolamine, [d] TON calculated as moles of $\mathrm{CO}$ divided by moles of catalyst.

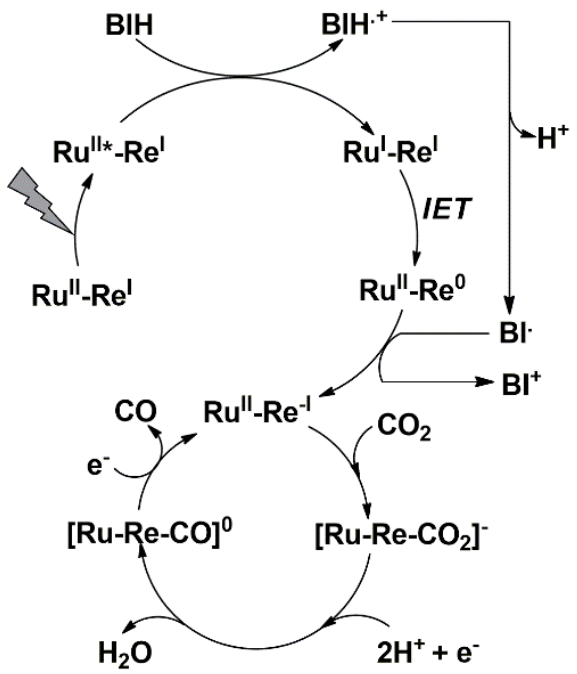

Figure 8. Proposed photocatalytic cycle for the Ru-cT-Re and similar systems. The $e^{-}$sources at the bottom cycle could come from either the $R u$ photoreductant or the highly reducing $\mathrm{Bl}^{\circ}$.

\section{Conclusion}


The design of supramolecular assemblies bridging a photosensitizer unit and a catalytic unit is revisited in this study by investigating photo-induced electron transfer processes in a novel triazole-linked $\mathrm{Ru}-\mathrm{Re}$ dyad. The triazole bridging ligand provided a weak electronic communication between the $\mathrm{Ru}$ and Re units with observed anodic shifts of the reduction potential of the latter. This resulted in a good thermodynamic drive $(\Delta G=-$ $220 \mathrm{meV}$ ) for the $1^{\text {st }} \mathrm{CSS}$ forming a formal $\mathrm{Ru}$ "-cT-Re ${ }^{0}$ occurring at a very fast apparent rate of $k_{a p p 1}=5.4( \pm 0.3) \times 10^{7} \mathrm{~s}^{-1}$ as determined by nanosecond flash photolysis. The possibility of photo-induced two-electron accumulation in the Re moiety was tracked by a pump-pump-probe transient absorption technique but results show a competitive intramolecular reverse electron transfer just regenerating back the $1^{\text {st }} \mathrm{CSS}$. The process of forming the more active doubly-reduced form of the Re catalyst is prevented by the highly endergonic process of electron transfer from the $\mathrm{Ru}^{\prime}$ photo-reductant, but can easily be overcome by using the non-innocent role of sacrificial electron donors providing highly reducing radical byproducts. The complementary and extensive investigations in this study point to substantial reconsiderations of supramolecular assembly design especially if such strategy will be employed in complete photo-electro-chemical cell applications.

\section{Experimental Section}

Synthesis of the reference compounds Ru-cT-Ph ${ }^{[35]}$ and $\mathbf{R e}{ }^{[50]}$ as well as the necessary precursors (compounds $\mathbf{A}$ and $\mathbf{B})^{[35]}$ for "click" chemistry and sacrificial electron donors ${ }^{[48,51,52]}$ are reported elsewhere. Ru photosensitizer was purchased from Sigma Aldrich in its dichloride form. All other chemical reagents used in the synthetic route were obtained from commercial sources as guaranteed-grade reagents and used without further purification. Water was Milli-Q filtered $(18.2 \mathrm{M} \Omega \cdot \mathrm{cm}$ at $\left.25^{\circ} \mathrm{C}\right)$. Proton and carbon nuclear magnetic resonance $\left({ }^{1} \mathrm{H}\right.$ and ${ }^{13} \mathrm{C}$ NMR) spectra were recorded at room temperature on Bruker Advance spectrometers. The electrospray ionization mass spectrometry (ESIHRMS) experiments were performed on TSQ (Thermo Scientific. 2009) with an $\mathrm{ESI}^{+}$method. Ground state absorption spectra were measured on a Specord double beam spectrophotometer (Analytik Jena).

\section{Synthesis of (bipyridine) ${ }_{2}$-(bipyridine-triazol-bipyridine-N-oxide)} ruthenium hexafluorophosphate (Compound $\mathrm{C}$ )

Compound A (203.2 mg, $0.23 \mathrm{mmol}, 1.0$ eq.) was suspended in $\mathrm{CH}_{2} \mathrm{Cl}_{2}$ $(11.5 \mathrm{~mL})$ under an argon atmosphere. Compound $\mathbf{B}(74.6 \mathrm{mg}, 0.35$ $\mathrm{mmol}, 1.5$ eq.) was added, followed by successive addition of water (11.5 $\mathrm{mL}$ ), sodium ascorbate $(20.5 \mathrm{mg}, 0.10 \mathrm{mmol}, 0.45$ eq.) and copper sulfate pentahydrate $(8.6 \mathrm{mg}, 0.03 \mathrm{mmol}, 0.15$ eq.). After 20 hours of stirring at room temperature, a saturated aqueous solution of ammonium hexafluorophosphate was added and the reaction mixture was extracted with $\mathrm{CH}_{2} \mathrm{Cl}_{2}$. The organic layers were washed with a saturated aqueous solution of $\mathrm{NaCl}$, and concentrated. The crude solid was dissolved in a minimum amount of $\mathrm{CH}_{2} \mathrm{Cl}_{2}$ then filtered through an alumina plug. The excess of azido derivative was removed by washing with $\mathrm{CH}_{2} \mathrm{Cl}_{2}$, and the desired ruthenium complex was recovered by washing with $\mathrm{CH}_{3} \mathrm{CN}$ and a solution of ammonium hexafluorophosphate in $\mathrm{CH}_{3} \mathrm{OH}$. The solvents were evaporated. The residue was dissolved in a minimum amount of $\mathrm{CH}_{2} \mathrm{Cl}_{2}$, then added drop wise at a large volume of pentane. The formed precipitate was filtered, washed several times with $\mathrm{H}_{2} \mathrm{O}$ and $\mathrm{Et}_{2} \mathrm{O}$ and dried under vacuum. Yield: $195.1 \mathrm{mg}, 0.18 \mathrm{mmol}, 77 \%$. ${ }^{1} \mathrm{H}$ NMR $(400$ $\left.\mathrm{MHz}, \mathrm{CD}_{3} \mathrm{CN}\right): \delta=9.15(\mathrm{~s}, 1 \mathrm{H}), 8.98(\mathrm{~d}, 1 \mathrm{H}, J=1.5 \mathrm{~Hz}), 8.92(\mathrm{~d}, 1 \mathrm{H}$, $J=8.0 \mathrm{~Hz}), 8.80(\mathrm{br} \mathrm{s}, 1 \mathrm{H}), 8.73(\mathrm{~d}, 1 \mathrm{H}, \mathrm{J}=3.2 \mathrm{~Hz}), 8.68(\mathrm{br} \mathrm{d}, 1 \mathrm{H}, J=8.0$ $\mathrm{Hz}), 8.55-8.47(\mathrm{~m}, 4 \mathrm{H}), 8.44(\mathrm{~d}, 1 \mathrm{H}, \mathrm{J}=7.1 \mathrm{~Hz}), 8.11$ (ddd, $1 \mathrm{H}, \mathrm{J}=8.0,7.9$, $1.4 \mathrm{~Hz}), 8.11-8.03(\mathrm{~m}, 4 \mathrm{H}), 8.02(\mathrm{dd}, 1 \mathrm{H}, J=8.0,7.3 \mathrm{~Hz}), 7.94(\mathrm{dd}, 1 \mathrm{H}$, $J=7.1,3.2 \mathrm{~Hz}), 7.86(\mathrm{dd}, 1 \mathrm{H}, J=5.9,1.5 \mathrm{~Hz}), 7.86(\mathrm{~m}, 1 \mathrm{H}), 7.81(\mathrm{~d}, 1 \mathrm{H}$,
$J=5.9 \mathrm{~Hz}), 7.79-7.73(\mathrm{~m}, 4 \mathrm{H}), 7.56(\mathrm{dd}, 1 \mathrm{H}, \mathrm{J}=7.3,4.3 \mathrm{~Hz}), 7.46-7.38(\mathrm{~m}$, $5 \mathrm{H}){ }^{13} \mathrm{C}$ NMR $\left(100 \mathrm{MHz}, \mathrm{CD}_{3} \mathrm{CN}\right): \delta=159.1-158.2,153.6,153.1-153.0$, $150.1,149.7,145.7,144.9,140.3,139.2,138.8,129.2,129.0,126.9$ 126.5, 125.9, 125.6, 124.3, 123.6, 121.4, 119.3, 118.6 HRMS (ESI $\left.{ }^{+}\right) \mathrm{m} / \mathrm{z}$ calcd for $\mathrm{C}_{42} \mathrm{H}_{31} \mathrm{~F}_{6} \mathrm{~N}_{11} \mathrm{OPRu}$ : 952.1404; found: $952.1370 ; \mathrm{m} / z$ calcd for $\mathrm{C}_{42} \mathrm{H}_{31} \mathrm{~N}_{11} \mathrm{ORu}: 403.5878$; found: 403.5870 .

Synthesis of ((bipyridine) $)_{2}$-(bipyridine-triazol-bipyridine) ruthenium hexafluorophosphate (Compound D)

To a solution of ruthenium complex (compound C) $(109.7 \mathrm{mg}, 0.1 \mathrm{mmol}$, 1.0 eq.) in dry $\mathrm{CH}_{2} \mathrm{Cl}_{2}(20 \mathrm{~mL})$ was added phosphorous trichloride $(26 \mu \mathrm{L}$, $41.2 \mathrm{mg}, 0.3 \mathrm{mmol}, 3.0$ eq.) at $0^{\circ} \mathrm{C}$ under an argon atmosphere. The reaction mixture was heated at reflux for 3 hours, then poured into an ice-water mixture and the $\mathrm{pH}$ of the aqueous phase was adjusted to 11 with an aqueous $\mathrm{NaOH}$ solution. The aqueous layer was extensively extracted with $\mathrm{CH}_{2} \mathrm{Cl}_{2}$. The organic layers were combined and washed with brine, then concentrated. The residue was dissolved in a minimum amount of $\mathrm{CH}_{2} \mathrm{Cl}_{2}$, then added dropwise at a large volume of pentane. The formed precipitate was filtered, washed several times with $\mathrm{H}_{2} \mathrm{O}$ and $\mathrm{Et}_{2} \mathrm{O}$ and dried under vacuum. Yield: $85.3 \mathrm{mg}, 0.079 \mathrm{mmol}, 79 \%{ }^{1} \mathrm{H}$ NMR $\left(400 \mathrm{MHz}, \mathrm{CD}_{3} \mathrm{CN}\right) \delta=9.28(\mathrm{~s}, 1 \mathrm{H}), 9.02(\mathrm{~d}, 1 \mathrm{H}, J=1.7 \mathrm{~Hz}), 8.94(\mathrm{~d}$, $1 \mathrm{H}, J=2.1 \mathrm{~Hz}), 8.90(\mathrm{~d}, 1 \mathrm{H}, J=5.3 \mathrm{~Hz}), 8.74(\mathrm{br} \mathrm{d}, 1 \mathrm{H}, J=4.6 \mathrm{~Hz}), 8.70(\mathrm{br}$ d, $1 \mathrm{H}, J=8.1 \mathrm{~Hz}$ ), 8.56-8.48 (m, 5H), 8.12 (ddd, $1 \mathrm{H}, J=8.1,7.7,1.3 \mathrm{~Hz}$ ), 8.11-8.03 (m, $4 \mathrm{H}), 7.97$ (ddd, $1 \mathrm{H}, \mathrm{J}=7.8,7.6,1.3 \mathrm{~Hz}$ ), 7.97 (dd, $1 \mathrm{H}, \mathrm{J}=5.3$, $2.1 \mathrm{~Hz}$ ), 7.91 (dd, $1 \mathrm{H}, J=6.0,1.7 \mathrm{~Hz}), 7.86(\mathrm{br} \mathrm{d}, 1 \mathrm{H}, J=5.5 \mathrm{~Hz}), 7.82(\mathrm{~d}$, $1 \mathrm{H}, J=6.0 \mathrm{~Hz}$ ), 7.79-7.73 (m, 4H), 7.49 (ddd, $1 \mathrm{H}, J=7.6,4.6,0.8 \mathrm{~Hz}$ ), 7.46-7.38 $(\mathrm{m}, 5 \mathrm{H}){ }^{13} \mathrm{C}$ NMR $\left(100 \mathrm{MHz}, \mathrm{CD}_{3} \mathrm{CN}\right) \delta=159.8,159.1,158.3$, $158.2,155.9,153.6,153.2-153.1,152.8,150.9,145.7,145.4,140.4$, 139.2, 138.9, 129.2, 129.0, 126.3, 125.9, 125.7, 124.4, 123.7, 122.5 121.5, 115.4, 111.9 HRMS (ESI $\left.{ }^{+}\right) \mathrm{m} / z$ calcd for $\mathrm{C}_{42} \mathrm{H}_{31} \mathrm{~F}_{6} \mathrm{~N}_{11} \mathrm{PRu}$ : 936.1454; found: $936.1436 ; \mathrm{m} / z$ calcd for $\mathrm{C}_{42} \mathrm{H}_{31} \mathrm{~N}_{11} \mathrm{Ru}$ : 395.5904; found: 395.5903.

\section{Synthesis of Ru-cT-Re}

To a solution of ruthenium complex (compound D) $(43.2 \mathrm{mg}, 0.04 \mathrm{mmol}$, 1.0 eq.) in $\mathrm{CH}_{3} \mathrm{CN}(7 \mathrm{~mL})$ and THF $(14 \mathrm{~mL})$ was added bromopentacarbonylrhenium (I) (16.2 $\mathrm{mg}, 0.04 \mathrm{mmol}, 1.0$ eq.) at room temperature under an argon atmosphere. The reaction mixture was heated at $60^{\circ} \mathrm{C}$ for 18 hours, then the reaction mixture was concentrated. The residue was suspended in a mixture of $\mathrm{CH}_{3} \mathrm{OH}$ and $\mathrm{H}_{2} \mathrm{O}$ with hexafluorophosphate salt. The suspension was kept in the fridge overnight. The formed precipitate was filtered, washed several times with $\mathrm{H}_{2} \mathrm{O}$ and $\mathrm{Et}_{2} \mathrm{O}$ and dried under vacuum. Yield: $49.2 \mathrm{mg}, 0.035 \mathrm{mmol}$, $86 \%{ }^{1} \mathrm{H}$ NMR $\left(400 \mathrm{MHz}, \mathrm{CD}_{3} \mathrm{CN}\right) \delta=9.57(\mathrm{~s}, 1 \mathrm{H}), 9.22(\mathrm{~d}, 1 \mathrm{H}, J=6.2 \mathrm{~Hz})$, $9.10(\mathrm{~d}, 1 \mathrm{H}, J=1.4 \mathrm{~Hz}$ ), 9.08 (ddd, $1 \mathrm{H}, J=5.5,1.4,0.6 \mathrm{~Hz}$ ), 8.95 (d, $1 \mathrm{H}$, $J=1.9 \mathrm{~Hz}$ ), $8.79(\mathrm{br} \mathrm{d}, 1 \mathrm{H}, J=8.1 \mathrm{~Hz}), 8.70(\mathrm{br} \mathrm{d}, 1 \mathrm{H}, J=8.2 \mathrm{~Hz}), 8.55-8.49$ ( $\mathrm{m}, 4 \mathrm{H}$ ), 8.24 (ddd, $1 \mathrm{H}, J=8.2,7.6,1.4 \mathrm{~Hz}$ ), 8.12 (ddd, $1 \mathrm{H}, J=8.1,7.9,1.4$ $\mathrm{Hz}$ ), 8.10 (dd, $1 \mathrm{H}, J=6.2,1.9 \mathrm{~Hz}$ ), 8.11-8.04 (m, $4 \mathrm{H}), 7.90$ (dd, $1 \mathrm{H}, J=6.0$, $1.4 \mathrm{~Hz}$ ), 7.87 (ddd, $1 \mathrm{H}, J=5.8,1.4,0.7 \mathrm{~Hz}$ ), $7.85(\mathrm{~d}, 1 \mathrm{H}, J=6.0 \mathrm{~Hz}), 7.79-$ $7.73(\mathrm{~m}, 4 \mathrm{H}), 7.69$ (ddd, $1 \mathrm{H}, J=7.6,5.5,1.0 \mathrm{~Hz}), 7.47-7.39(\mathrm{~m}, 5 \mathrm{H}){ }^{13} \mathrm{C}$ NMR $\left(100 \mathrm{MHz}, \mathrm{CD}_{3} \mathrm{CN}\right) \delta=159.5,159.3,158.3,158.3,156.5,156.3$ $154.8,153.8,153.2-153.0,146.2,141.4,139.9,139.3,129.6,129.2$, $129.0,126.1,126.0,125.7,124.4,124.3,121.6,118.2,115.3$ HRMS $\left(\mathrm{ESI}^{+}\right) \mathrm{m} / \mathrm{z}$ calcd for $\mathrm{C}_{45} \mathrm{H}_{31} \mathrm{BrF}_{6} \mathrm{~N}_{11} \mathrm{O}_{3} \mathrm{PReRu}$ : 1286.0026; found: 1286.0079; $\mathrm{m} / \mathrm{z}$ calcd for $\mathrm{C}_{45} \mathrm{H}_{31} \mathrm{BrN}_{11} \mathrm{O}_{3} \mathrm{ReRu}$ : 570.5189; found: 570.5221 .

\section{Electrochemical Characterization}

Cyclic voltammetry measurements were performed in an electrochemical cell composed of a glassy carbon ( $3 \mathrm{~mm}$ diameter) working electrode, $\mathrm{Ag} / \mathrm{AgNO}_{3}\left(10^{-2} \mathrm{M}\right)$ reference electrode, and a platinum wire counter electrode. Acetonitrile was mainly used as solvent and solutions of samples were prepared at a concentration of $1 \mathrm{mM}$. Tertbutylammonium hexafluorophosphate (TBAP) was used as supporting electrolyte and its concentration was maintained at hundredfold excess compared to the sample. The solutions were all purged with inert argon gas. Ferrocene was used as a reference for standard comparison in all experiments. Scan rate was chosen at $100 \mathrm{mV} / \mathrm{s}$ and a $\mathrm{CH}$ Instruments potentiostat 
workstation was utilized to control the applied voltages and to measure resulting current.

\section{Nanosecond Transient Absorption Spectroscopy}

Single and double pump nanosecond transient absorption measurements were performed on a home-built set-up at which has been described in detail previously. ${ }^{[34]}$ One or two Nd:YAG pumped optical parametric oscillator (OPO) lasers are used for sample excitation at $460 \mathrm{~nm}$ with an energy of $\sim 6.5 \mathrm{~mJ}$ per pulse. The first pump operates at $20 \mathrm{~Hz}$, whereas the second one has a repetition rate at $10 \mathrm{~Hz}$. After excitation, the sample is probed with a pulsed nanosecond white light continuum laser at a repetition rate of $20 \mathrm{~Hz}$. The probe beam is split into two arms, one for probing the sample and the other for reference in order to compensate for the pulse-to-pulse energy fluctuation. The probing arm after passing through the sample is coupled to a round to linear optical fiber bundle before being analyzed with a spectrograph SPEX $270 \mathrm{M}$ (Jobin-Yvon). The detection of the dispersed white light is performed with an intensified CCD (ICCD) detector PIMAX 4 (Princeton Instrument). For the pump-probe experiments, only one excitation laser with a repetition rate at $10 \mathrm{~Hz}$ is employed. For the pump-pump-probe experiments, the setup is operated in the online subtraction mode in which the transient absorption after the first excitation is inherently removed by running the first pump at $20 \mathrm{~Hz}$ having the same repetition rate as the probe.

\section{Photocatalytic Set-up and Product Characterization}

Photocatalytic experiments were made in a modified quartz cuvette with a total volume of $6.85 \mathrm{~mL}$, thermostated at $20^{\circ} \mathrm{C}$, and sealed with a rubber septum. About $3.0 \mathrm{~mL}$ solutions of photocatalysts, and sacrificial electron donor were dissolved in appropriate solvents and were purged with $\mathrm{CO}_{2}$ for 15 minutes. A SugarCUBE high intensity LED fiber optic illuminator was utilized with a blue light output centered at $463 \mathrm{~nm}$ with a full width at half maximum (FWHM) characteristic of about $50 \mathrm{~nm}$. The source was adjusted to produce the lowest light intensity of $180 \mathrm{~W} / \mathrm{m}^{2}$ and the actual incident light power reaching the exposed cross section of the cuvette was $82 \mathrm{~mW}$, as measured by a power meter. Gas chromatography was utilized to detect $\mathrm{CO}$ from the photocatalytic reduction of $\mathrm{CO}_{2}$. For gas analysis, $50 \mathrm{uL}$ gas aliquots were withdrawn from the head space of the cuvette with a gas-tight syringe and injected into the Trace GC Ultra, Thermo Scientific equipped with a $30 \mathrm{~m}$ molecular sieve porous layer open tubular (PLOT) column having an internal diameter of $0.53 \mathrm{~nm}$, helium carrier gas, and a thermal conductivity detector (TCD). Peak separation between $\mathrm{O}_{2}, \mathrm{~N}_{2}, \mathrm{CO}$, and $\mathrm{CO} 2$ were achieved by programming the oven temperature from an initial $40{ }^{\circ} \mathrm{C}$ for 6 minutes, ramped by $20^{\circ} \mathrm{C} / \mathrm{min}$ until a final temperature of $250{ }^{\circ} \mathrm{C}$ held for 2 minutes. A splitless injector line was utilized to maximize the injection volume and become sensitive to possible trace amounts. A calibration curve relating peak area and concentration of $\mathrm{CO}$ was established by injecting known amounts of pure $\mathrm{CO}$, and this calibration curve was used to determine actual amounts of $\mathrm{CO}$ produced. Turnover number (TON) was then calculated by dividing the moles of $\mathrm{CO}$ produced by the moles of catalyst consumed.

\section{Acknowledgements}

This work was supported by the French National Research Agency (ANR-19-CE05-0020-02, LOCO) and by the French Infrastructure for Integrated Structural Biology (FRISBI) ANR-10INSB-05-01.

Keywords: carbon dioxide $\cdot$ rhenium catalyst $\bullet$ supramolecular chemistry $\cdot$ electron transfer $\cdot$ photocatalysis
[1] J. Hawecker, J.-M. Lehn, R. Ziessel, J. Chem. Soc., Chem. Commun 1983, 536-538.

[2] J. Hawecker, J.-M. Lehn, R. Ziessel, Helvetica chimica acta 1986, 69 , 1990-2012.

[3] J. M. Smieja, E. E. Benson, B. Kumar, K. A. Grice, C. S. Seu, A. J. M. Miller, J. M. Mayer, C. P. Kubiak, Proc. Natl. Acad. Sci. USA 2012, 109, $15646-15650$

[4] H. Hori, K. Koike, M. Ishizuka, K. Takeuchi, T. Ibusuki, O. Ishitani, J. Organomet. Chem. 1997, 530, 169-176.

[5] H. Tsubaki, S. Tohyama, K. Koike, H. Saitoh, O. Ishitani, Dalton Trans. 2005, 0, 385-395

[6] H. Tsubaki, A. Sekine, Y. Ohashi, K. Koike, H. Takeda, O. Ishitani, J. Am. Chem. Soc. 2005, 127, 15544-15555.

[7] P. Kurz, B. Probst, B. Spingler, R. Alberto, European Journal of Inorganic Chemistry 2006, 2006, 2966-2974.

[8] H. Takeda, K. Koike, H. Inoue, O. Ishitani, J. Am. Chem. Soc. 2008, 130, 2023-2031.

[9] J. M. Smieja, C. P. Kubiak, Inorg. Chem. 2010, 49, 9283-9289.

[10] A. J. Huckaba, E. A. Sharpe, J. H. Delcamp, Inorg. Chem. 2016, 55, $682-690$.

[11] Y. Yamazaki, H. Takeda, O. Ishitani, J. Photochem. Photobiol. C 2015, $25,106-137$

[12] Y. Tamaki, O. Ishitani, ACS Catal. 2017, 7, 3394-3409.

[13] Y. Tamaki, K. Koike, T. Morimoto, O. Ishitani, J. Catal. 2013, 304, $22-$

[14] Z.-Y. Bian, S.-M. Chi, L. Li, W. Fu, Dalton Trans. 2010, 39, 7884

[15] Z.-Y. Bian, H. Wang, W.-F. Fu, L. Li, A.-Z. Ding, Polyhedron 2012, 32, 78-85

[16] B. Gholamkhass, H. Mametsuka, K. Koike, T. Tanabe, M. Furue, O. Ishitani, Inorg. Chem. 2005, 44, 2326-2336.

[17] S. Meister, R. O. Reithmeier, A. Ogrodnik, B. Rieger, ChemCatChem 2015, 7, 3562-3569.

[18] S. Sato, K. Koike, H. Inoue, O. Ishitani, Photochem. Photobiol. Sci. 2007, 6, 454-461.

[19] Z.-Y. Bian, K. Sumi, M. Furue, S. Sato, K. Koike, O. Ishitani, Dalton Trans. 2009, 983-993.

[20] K. Koike, S. Naito, S. Sato, Y. Tamaki, O. Ishitani, J. Photochem Photobiol. A 2009, 207, 109-114.

[21] Y. Yamamoto, Y. Tamaki, T. Yui, K. Koike, O. Ishitani, Journal of the American Chemical Society 2010, 132, 11743-11752.

[22] A. Nakada, K. Koike, T. Nakashima, T. Morimoto, O. Ishitani, Inorg. Chem. 2015, 54, 1800-1807.

[23] Y. Ueda, H. Takeda, T. Yui, K. Koike, Y. Goto, S. Inagaki, O. Ishitani, ChemSusChem 2015, 8, 439-442.

[24] T. L. Easun, W. Z. Alsindi, M. Towrie, K. L. Ronayne, X.-Z. Sun, M. D. Ward, M. W. George, Inorg. Chem. 2008, 47, 5071-5078.

[25] K. Koike, D. C. Grills, Y. Tamaki, E. Fujita, K. Okubo, Y. Yamazaki, M.

Saigo, T. Mukuta, K. Onda, O. Ishitani, Chem. Sci. 2018, 9, 2961-2974.

[26] L. Frayne, N. Das, A. Paul, S. Amirjalayer, W. J. Buma, S. Woutersen, C. Long, J. G. Vos, M. T. Pryce, ChemPhotoChem 2018, 2, 323-331. [27] E. Kato, H. Takeda, K. Koike, K. Ohkubo, O. Ishitani, Chem. Sci. 2015, 6, 3003-3012.

[28] C. M. Brown, T. Auvray, E. E. DeLuca, M. B. Ezhova, G. S. Hanan, M. O. Wolf, Chem. Commun. 2020, 56, 10750-10753.

[29] F. P. A. Johnson, M. W. George, F. Hartl, J. J. Turner, Organometallics 1996, 15, 3374-3387.

[30] P. Christensen, A. Hamnett, A. V. G. Muir, J. A. Timney, Journal of the Chemical Society, Dalton Transactions 1992, 0, 1455-1463.

[31] B. P. Sullivan, C. M. Bolinger, D. Conrad, W. J. Vining, T. J. Meyer, J. Chem. Soc., Chem. Commun. 1985, 0, 1414-1416.

[32] H. C. Kolb, M. G. Finn, K. B. Sharpless, Angewandte Chemie International Edition 2001, 40, 2004-2021.

[33] A. Baron, C. Herrero, A. Quaranta, M.-F. Charlot, W. Leibl, B.

Vauzeilles, A. Aukauloo, Chem. Commun. 2011, 47, 11011-11013.

[34] S. Mendes Marinho, M.-H. Ha-Thi, V.-T. Pham, A. Quaranta, T. Pino, C. Lefumeux, T. Chamaillé, W. Leibl, A. Aukauloo, Angew. Chem. Int. Ed 2017, $56,15936-15940$.

[35] A. Baron, C. Herrero, A. Quaranta, M.-F. Charlot, W. Leibl, B.

Vauzeilles, A. Aukauloo, Inorg. Chem. 2012, 51, 5985-5987.

[36] C. Herrero, A. Quaranta, M. Sircoglou, K. Sénéchal-David, A. Baron, I. M. Marín, C. Buron, J.-P. Baltaze, W. Leibl, A. Aukauloo, F. Banse, Chem Sci. 2015, 6, 2323-2327.

[37] C. Herrero, A. Quaranta, S. El Ghachtouli, B. Vauzeilles, W. Leibl, A. Aukauloo, Physical Chemistry Chemical Physics 2014, 16, 12067.

[38] A. Juris, V. Balzani, F. Barigelletti, S. Campagna, P. I Belser, A. Von Zelewsky, Coordination Chemistry Reviews 1988, 84, 85-277.

[39] K. Kalyanasundaram, J. Chem. Soc., Faraday Trans. 2 1986, 82 2401-2415.

[40] P. Gotico, A. Del Vecchio, D. Audisio, A. Quaranta, Z. Halime, W. Leibl, A. Aukauloo, ChemPhotoChem 2018, 2, 715-719.

[41] Y. F. Lee, J. R. Kirchhoff, R. M. Berger, D. Gosztola, J. Chem. Soc.,

Dalton Trans. 1995, 0, 3677-3682.

[42] L. Hammarström, Acc. Chem. Res. 2015, 48, 840-850. 
[43] R. Lomoth, T. Häupl, O. Johansson, L. Hammarström, Chemistry - A European Journal 2002, 8, 102-110.

[44] L. Flamigni, E. Baranoff, J.-P. Collin, J.-P. Sauvage, B. Ventura

ChemPhysChem 2007, 8, 1943-1949.

[45] M. Kuss- Petermann, O. S. Wenger, Helvetica Chimica Acta 2017, 100 DOI 10.1002/hlca.201600283.

[46] M. Skaisgirski, X. Guo, O. S. Wenger, Inorg. Chem. 2017, 56, 2432-

2439.

[47] M.-H. Ha-Thi, V.-T. Pham, T. Pino, V. Maslova, A. Quaranta, C

Lefumeux, W. Leibl, A. Aukauloo, Photochem. Photobiol. Sci. 2018, 17, 903-

909.

[48] X.-Q. Zhu, M.-T. Zhang, A. Yu, C.-H. Wang, J.-P. Cheng, J. Am. Chem Soc. 2008, 130, 2501-2516.

[49] Y. Pellegrin, F. Odobel, Comptes Rendus Chimie 2017, 20, 283-295.

[50] E. Portenkirchner, K. Oppelt, C. Ulbricht, D. A. M. Egbe, H.

Neugebauer, G. Knör, N. S. Sariciftci, Journal of Organometallic Chemistry 2012, 716, 19-25.

[51] D. Mauzerall, F. H. Westheimer, J. Am. Chem. Soc. 1955, 77, 2261-

2264.

[52] E. Hasegawa, T. Seida, N. Chiba, T. Takahashi, H. Ikeda, J. Org

Chem. 2005, 70, 9632-9635. 


\section{Entry for the Table of Contents}

Insert graphic for Table of Contents here.

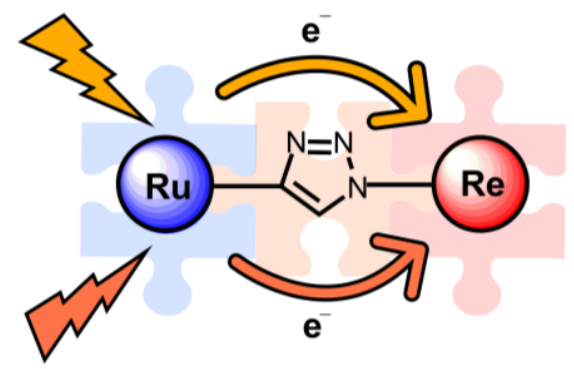

A dyad consisting of a ruthenium photosensitizer linked to a rhenium catalyst by a triazole bridge was scrutinized for photo-induced charge accumulation. A first charge-separated state was formed upon excitation and intramolecular electron transfer, but second excitation did not allow charge accumulation. Regardless, the dyad showed good photocatalytic activity towards $\mathrm{CO}_{2}$ reduction, hinting the non-innocent role of byproducts in solution.

Institute and/or researcher Twitter usernames: @CEA_Joliot, @I2BCParisSaclay, @ISMOlab_Orsay, @UnivParisSaclay 